\title{
Clinical impact of COVID-19 on a French population of spondyloarthritis patients
}

\author{
Christian Hubert Roux ${ }^{1,2}$ (D) $\cdot$ O. Brocq ${ }^{3} \cdot$ F. Gerald ${ }^{1} \cdot$ C. Pradier ${ }^{4} \cdot$ L. Bailly ${ }^{4}$
}

Received: 30 June 2020 / Revised: 4 September 2020 / Accepted: 16 September 2020 / Published online: 24 September 2020

(C) International League of Associations for Rheumatology (ILAR) 2020

\section{Dear Editor,}

Severe acute respiratory syndrome coronavirus 2 (SARS-CoV-2)-mediated coronavirus disease 2019 (COVID-19) has raised many questions regarding chronic inflammatory arthritides such as risks of using biological disease-modifying antirheumatic drugs (bDMARDs) or nonsteroidal anti-inflammatory drugs (NSAIDs) [1], which are widely used in spondyloarthritis (SpA). Possible deleterious effects have been suggested [2], and recent observations from the rheumatologic community have required us to evaluate this evolving medical situation [3, 4]. Since the impact of COVID-19 on inflammatory rheumatic diseases is not well elucidated [5], a survey in a population with $\mathrm{SpA}$ was conducted herein. A questionnaire was administered using a private social network of the "Association contre les spondylarthrites" (ACS) in 1656 members on Thursday, April 30, 2020. The questionnaire was created using Microsoft Forms software (Microsoft Corp., Redmond, WA, USA). It included questions on age, body mass index (BMI), diseases, NSAIDs and bDMARDs, clinical manifestations of COVID-19 (detailed in Table 1), confirmed or suspected COVID-19 and possible hospitalisation.

A written explanation of the aim of this study was given with the questionnaire. The study protocol was approved by the national ethics commission (CNIL)

Christian Hubert Roux

Roux.c2@chu-nice.fr

1 Rheumatology Department, University hospital Nice, University Cote D'azur, Nice, France

2 Laboratory LAMHESS, Université Cote d'Azur, Nice, France

3 Rheumatology Department, CHPG Monaco, Monaco City, Monaco

4 Department of Public Health, University Hospital Centre Nice, Université Cote d'Azur, Nice, France and registered by "L'institut national des données de santé" (MR 4316150420; Clinical trial number: NCT04355923). Out of 1656 members, 611 (37\%) responded to the questionnaire. The mean age of the participants was 47 years $( \pm 11.8)$. The mean BMI was $25.9( \pm 5.2)$. Overall, $406(66 \%)$ and $380(62 \%)$ patients were treated with bDMARDS and NSAIDs, respectively. Co-prescription was frequent in $37 \%$ of the participants (225/611). Overall, $460(75 \%)$ declared one or more symptoms possibly linked to COVID-19. Analysis of the association between NSAIDs use and declared cases suspected of COVID-19 showed a significant trend $(p=0.05)$. Similar result was not obtained regarding bDMARD use. As a possible consequence of media warnings, the onset of symptoms and suspicion of the disease were associated with decline in or discontinuation of NSAID $(p=0.01)$ and bDMARD treatment $(p=0.04)$.

Present data on the impact of COVID-19 on SpA can assist rheumatologists in their patients counselling and management. Although our findings cannot indicate the incidence rate of COVID-19, the few numbers of confirmed and suspected cases are similar to previously reported results [5]. This situation can be explained by not only non-systematisation of tests in France but also confinement and limited access to practitioners.

Since only one patient was hospitalised, the frequency of evocative symptoms might have not included those in intensive care at the moment of the survey. Although many of these symptoms are non-specific, ageusia and dyspnoea remain suggestive and were only found in patients with NSAIDs or bDMARDs. A significant number of participants were administered bDMARDs. It has been postulated that the use of TNF inhibitors may be effective in reducing both SARS-CoV2 infection and consequent organ damage [6]. It is important to assess the use of NSAIDs in further clinical studies of COVID-19 as there have been 
Table 1 Clinical characteristics of the patients who participated in the survey

\begin{tabular}{|c|c|c|c|c|c|}
\hline & $\begin{array}{l}\text { All } \\
\text { patients }\end{array}$ & $\begin{array}{l}\text { Without } \\
\text { treatment }\end{array}$ & $\begin{array}{l}\text { NSAIDs } \\
\text { only }\end{array}$ & $\begin{array}{l}\text { bDMARD } \\
\text { only }\end{array}$ & $\begin{array}{l}\text { NSAIDs } \\
+ \\
\text { bDMARD }\end{array}$ \\
\hline Number of patients & 611 & 50 & 155 & 181 & 225 \\
\hline Age mean (SD) & $47(11.8)$ & $47(11.5)$ & $48(11.4)$ & $47(11.5)$ & $46(12.6)$ \\
\hline BMI mean (SD) & $25.9(5.2)$ & $25.2(3.7)$ & $25.6(5.0)$ & $26.1(5.4)$ & $26.0(5.7)$ \\
\hline \multicolumn{6}{|l|}{ Comorbidities $n /$ total (\%) } \\
\hline \multicolumn{6}{|l|}{ Smoking } \\
\hline Current smoker & $113 / 598(19 \%)$ & $8(16 \%)$ & $22(14 \%)$ & $42(23 \%)$ & $41(18 \%)$ \\
\hline Former smoker & $224 / 598(37 \%)$ & $20(40 \%)$ & $62(40 \%)$ & $60(33 \%)$ & $82(36 \%)$ \\
\hline No smoker & $261 / 598(43 \%)$ & $22(44 \%)$ & $67(43 \%)$ & $75(41 \%)$ & $97(43 \%)$ \\
\hline High blood pressure & 97/611 (16\%) & $15(30 \%)$ & $22(14 \%)$ & $27(15 \%)$ & $33(15 \%)$ \\
\hline Diabetes & $22 / 611(4 \%)$ & $2(4 \%)$ & $3(2 \%)$ & $5(3 \%)$ & $12(5 \%)$ \\
\hline Kidney failure & $15 / 611(2 \%)$ & $2(4 \%)$ & $2(1 \%)$ & $6(3 \%)$ & $5(2 \%)$ \\
\hline Psoriasis & $135 / 611(22 \%)$ & $8(16 \%)$ & $35(23 \%)$ & $39(22 \%)$ & $53(24 \%)$ \\
\hline Inflammatory bowel disease & $63 / 611(10 \%)$ & $4(8 \%)$ & $18(12 \%)$ & $16(9 \%)$ & $25(11 \%)$ \\
\hline Symptoms $n /$ total (\%) & $460 / 611(75 \%)$ & $33(66 \%)$ & $125(81)$ & $128(71)$ & $174(77)$ \\
\hline Fever & $79 / 611(13 \%)$ & $5(10 \%)$ & $18(12 \%)$ & $24(13 \%)$ & $32(14 \%)$ \\
\hline Non-productive cough & $148 / 611(24 \%)$ & $10(20 \%)$ & $34(22 \%)$ & $54(30 \%)$ & $50(22 \%)$ \\
\hline Asthenia $n /$ total (\%) & $460 / 611(75 \%)$ & $33(66 \%)$ & $125(81 \%)$ & $128(71 \%)$ & $174(77 \%)$ \\
\hline Myalgia & $263 / 611(43 \%)$ & $23(46 \%)$ & $74(48 \%)$ & $65(36 \%)$ & $101(45 \%)$ \\
\hline Anosmia/dysgeusia & $20 / 611(3 \%)$ & $0(0 \%)$ & $7(5 \%)$ & $5(3 \%)$ & $8(4 \%)$ \\
\hline Dyspnoea & $110 / 611(18 \%)$ & $11(22 \%)$ & $26(17 \%)$ & $37(20 \%)$ & $36(16 \%)$ \\
\hline Headache & $234 / 611(38 \%)$ & $19(38 \%)$ & $62(40 \%)$ & $62(34 \%)$ & $91(40 \%)$ \\
\hline Diarrhoea/nausea/vomiting & $106 / 611(17 \%)$ & $6(12 \%)$ & $29(19 \%)$ & $30(17 \%)$ & $41(18 \%)$ \\
\hline Diagnostic evocated $n(\%)$ & $40 / 576(7 \%)$ & $0(0 \%)$ & $12(8 \%)$ & $15(9 \%)$ & $13(6 \%)$ \\
\hline Rhinopharyngeal swabs $n(\%)$ & $17 / 40(42 \%)$ & $0(0 \%)$ & $7(58 \%)$ & $6(40 \%)$ & $4(31 \%)$ \\
\hline Positive swab test $n(\%)$ & $1(0.2 \%)$ & & $1(\%)$ & & \\
\hline Hospital admission $n(\%) *$ & $1(0.2 \%)$ & $1(1 \%)$ & & & \\
\hline
\end{tabular}

*Not in intensive care

unfounded warnings against the use of these drugs, which subsequently contributed to confusion in the general audience and medical community [2]. The reported association between asthenia and myalgia onset and NSAIDs use may be linked to the clinical course of SpA. In a precedent survey in press, we found more flare-ups possibly linked to confinement. Our survey in patients with SpA and their NSAID and bDMARD usage underlined the low impact of the pandemic on our population as well as the difficulty to interpret reportedrelated symptoms that can be linked to the clinical course of $\mathrm{SpA}$.

Authors' contributions All authors contributed to the study conception and design. Material preparation, data collection and analysis were performed by Christian Roux, Olivier Brocq, Franck Gerald, Christian Pradier and Laurent Bailly. The first draft of the manuscript was written by Christian Roux, and all authors commented on previous versions of the manuscript. All authors read and approved the final manuscript.

\section{Compliance with ethical standards}

Disclosures None.

Ethical approval The study protocol was approved by the National Ethics Commission (CNIL) and registered by "L'institut national des données de santé" (MR 4316150420; Clinical trial number: NCT04355923).

Consent to participate Not applicable.

Consent for publication Not applicable.

\section{References}

1. FitzGerald GA (2020) Misguided drug advice for COVID-19. Science 367:1434

2. Giollo A, Adami G, Gatti D, Luca I, Rossini M (2020) Coronavirus disease 19 (Covid-19) and non-steroidal anti-inflammatory drugs 
(NSAID). Ann Rheum Dis. https://doi.org/10.1136/annrheumdis2020-217598

3. Jethwa H, Sullivan A, Abraham S (2020) COVID-19 and rheumatology patients on immunomodulatory therapy - can we extrapolate data from previous viral pandemics? J Rheumatol. https://doi.org/10. 3899/jrheum.200527

4. Mikuls TR, Johnson SR, Fraenkel L, Arasaratnam RJ, Baden LR, Bermas BL, Chatham W, Cohen S, Costenbader K, Gravallese EM, Kalil AC, Weinblatt ME, Winthrop K, Mudano AS, Turner A, Saag KG (2020) American College of Rheumatology guidance for the management of adult patients with rheumatic disease during the COVID-19 pandemic. Arthritis Rheum 72:1241-1251. https://doi. org/10.1002/art.41301
5. Monti S, Balduzzi S, Delvino P, Bellis E, Quadrelli VS, Montecucco C (2020) Clinical course of COVID-19 in a series of patients with chronic arthritis treated with immunosuppressive targeted therapies. Ann Rheum Dis 79:667-668

6. Favalli E, Ingegnoli F, Lucia O, Cincinelli G, Cimaz R, Caporali R (2020) COVID-19 infection and rheumatoid arthritis: Faraway, so close! Autoimmun Rev 19:102523

Publisher's note Springer Nature remains neutral with regard to jurisdictional claims in published maps and institutional affiliations. 